Original Research

\title{
Study on Runoff Evaluation Law in the Luanhe River Basin, China
}

\author{
Chengju Shan ${ }^{1 *}$, Zengchuan Dong², Dongjing Huang ${ }^{1}$, Yaoru Lu ${ }^{2}$, Wei Xu ${ }^{2}$, Yi Zhang \\ ${ }^{1}$ Key Laboratory for Technology in Rural Water Management of Zhejiang Province, \\ Zhejiang University of Water Resources and Electric Power \\ ${ }^{2}$ College of Hydrology and Water Resources, Hohai University \\ ${ }^{3}$ Water Resources Bureau of Kaizhou District, Chongqing, China
}

Received: 28 February 2020

Accepted: 9 April 2020

\begin{abstract}
In the last 50 years, large changes in the runoff processes of the Luanhe River Basin have exacerbated the scarcity and spatiotemporal variability of water resources. It is both theoretically and practically important to study the characteristics, trends and periods of runoff changes in the Luanhe River Basin. In this study, the moving average method, the Mann-Kendall test and wavelet analysis are applied to analyze the evolution of the natural runoff of the Luanhe River using runoff data for 1959-2018 at the representative stations in the Luanhe River Basin, namely, the Goutaizi, Sandaohezi and Luan County stations. The results show that the runoff volumes at the three stations decreased for 1959-2018, including abrupt decreases at the Goutaizi station in 1969 and at the Sandaohezi station in 1976. The Luan County station exhibited a significant increase in runoff after 1997. The significant periods of variation in the runoff for the upper, middle and lower reaches of the Luanhe River are 28 years, 27 years and 30 years, respectively.
\end{abstract}

Keywords: runoff, trend analysis, Mann-Kendall test, wavelet, Luanhe River

\section{Introduction}

River water is necessary for production, livelihood and ecological balance [1]. Changes in river runoff directly affect the development and utilization of water resources [2] and thereby societal and economic development [3]. Studying the evolution of runoff and its influencing factors can provide a scientific basis for the management, protection and sustainable use of water resources $[4,5]$.

*e-mail: shancj@hhu.edu.cn
The change in river runoff is an important manifestation of climatic influence, especially precipitation and human activities in basins [6]. Thus, river runoff is an active area in global change research $[7,8]$. The fifth assessment report of the United Nations Intergovernmental Panel on Climate Change (IPCC) predicts that in the $21^{\text {st }}$ century, global climate change will increase surface runoff in high-latitude regions and humid tropical regions and decrease surface runoff in most arid subtropical regions and Mediterranean regions [7]. However, the causes of runoff changes are complex. Although climate change [8,9] (e.g., precipitation) is the main influence in river runoff changes, the potential increase in evapotranspiration is also considered to be 
a factor [12]. Human activity is a dominant factor in changing river runoff $[10,11]$ (e.g., land use and land cover changes have been shown to significantly impact runoff $[12,13])$. The leading factors of runoff change vary along the course of a river [14]. The scale of the change in runoff also matters, and studies have shown different runoff changes and hydrological responses for sub-basins of different scales in the same watershed. The Xia Jun research group [15] showed that climate change was the main influencing factor in the slight decrease in the runoff in the upper reaches of the Yangtze River and the slight increase in the runoff for the Jinsha River basin, a tributary. However, human activity has been used to explain approximately half of the significant decrease in the runoff of the tributaries of the Minjiang and Jialing rivers, and this degree of impact may increase in the future. Current research on runoff change in China mainly considers large watersheds, and few studies have been performed on small watersheds.

Significance test results show a decrease in the measured surface runoff at the main control stations of the six major rivers in China over the last 50 years. The Haihe and Luanhe river basins are where China's water resources are most vulnerable to climate change and the attenuation of water resources is the most prominent. In the last 20 years, precipitation in the Haihe river basin has decreased by $10 \%$, and surface water resources have decreased by $41 \%$. These climatic changes are expected to continue until 2040 [16]. Changes in runoff characteristics directly affect the development and utilization of water resources and thus economic and societal security and ecosystems. Therefore, research on the evolution of river runoff and its influencing factors can be used to manage and protect water resources. Continuous data monitoring can provide scientific evidence of environmental changes.

The Luanhe River Basin region in China is undergoing rapid economic development, and economic centers, such as Chengde, Tangshan and Qinhuangdao, have formed. Regional economic development is increasingly dependent on water resources, and the Panjiakou Reservoir is an important control project in the Luanhe River Basin for supplying water to the Tianjin, Tangshan and Xiaxia irrigation districts. However, the significant decrease in runoff into the reservoir over recent years has resulted in recurring water supply crises $[17,18]$. The trends in and causes of runoff changes in the basin serve as an important reference for the rational planning and utilization of water resources and the construction of ecological environments in the region.

In this study, nearly 60 years of hydrological data for the Luanhe River Basin are used in conjunction with the moving average method, the Mann-Kendall method, and the wavelet analysis method to analyze the basic runoff change and the change cycle and to determine the abrupt year. The results of this study can serve as a basis for decision-making in the management and comprehensive utilization of water resources and the management of soil erosion in the basin.

\section{Materials and Methods}

\section{Study Area and Data}

The Luanhe River originates in the northern foot of Bayanguertu Mountain in the Zhangjiakou area of Hebei Province (Fig. 1). The Shandian River turns southeast through Duolun County of the Inner Mongolia Autonomous Region and after flowing past the Xiaoluanhe River becomes the upper reach of the Luanhe River. The middle reach of the Luauhe River passes through the Yanshan Mountains, and the lower reach flows into Bohai Bay through a $50-\mathrm{km}$-wide delta. The Luanhe River is $888 \mathrm{~km}$ long with a $5.44 \times 104-\mathrm{km}^{2}$ basin. The multi-year average runoff is $59.3 \times 108 \mathrm{~m}^{3}$ for a depth of $109 \mathrm{~mm}$. The main branches include the Yixun River, the Wulie River, the Baohe River, the Sahe River and the Qinglong River. The basin $\left(115^{\circ} 34^{\prime}-119^{\circ} 50^{\prime} \mathrm{E}, 39^{\circ} 02^{\prime}-42^{\circ} 43^{\prime} \mathrm{N}\right)$ is located in the northeastern region of the North China Plain, where a temperate continental monsoon climate dominates, that is, cold, dry winters and hot, rainy summers. The multi-year average temperature in the basin is $7.6^{\circ} \mathrm{C}$, and the multi-year average precipitation is $520 \mathrm{~mm}$. The terrain causes the precipitation to gradually increase in a northerly direction from the coast and gradually decrease after passing the Great Wall. Concentrated rainfall and frequent rainstorms are unique features of the climate in this region. The upper reach of the basin includes the Bashang and Weichang plateau regions, and the ground surface exhibits wave-like undulation with widely distributed wind erosion depressions. The middle reach of the basin covers the North Hebei and Yanshan hilly areas, where the river valley is deep. The lower reach includes the piedmont plain of the

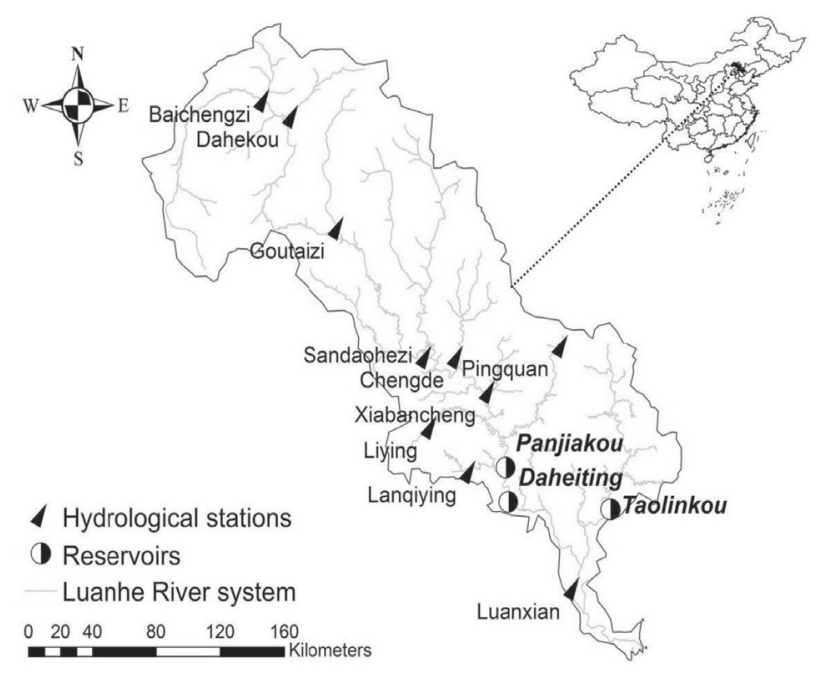

Fig. 1. Location of the Luanhe River. 
Yanshan Mountains and the delta plain of the Luanhe River and is considerably impacted by human activity. At the end of the 1970s, Panjiakou, Daheiting and other large controlling backbone water conservancy projects were constructed along the main stream of the Luanhe River to alleviate the disparity between the supply and demand of water resources in the Beijing-Tianjin area and to satisfy the water demand in Tangshan, Qinhuangdao and other centers of economic growth. In the 1990s, the Taolinkou Reservoir was constructed on the Qinglong River, a primary tributary of the Luanhe River, followed a series of supporting projects, such as the diversion of the Luanhe River into Tianjin, the diversion of the Luanhe River into Tangshan and the diversion of the Qinglong River into Qinhuangdao. The intensity of the development and utilization of water resources continues to increase [19].

In this study, measuring stations were selected for their representativeness of the river basin and the reliability and integrity of the obtainable data. The Goutaizi, Sandaohezi and Luanxian stations on the main stream of the Luanhe River were selected as representative hydrological stations on the upper, middle and lower reaches, respectively, of the Luanhe River Basin for the runoff analysis of change trends (Table 1). Runoff data were obtained from 1959 to 2018. The Tyson polygon distribution was used to determine the surface precipitation in the basin from the precipitation data at the meteorological stations and around the basin. The correlation coefficients between the precipitation and the runoff in the catchment area above the Goutaizi, Sandaohezi and Shexian Stations were $0.826,0.719$ and 0.847 , respectively.

\section{Methods}

In this study, we adopted the moving average method and the Mann-Kendall (M-K) rank correlation test. We conducted a trend analysis on the time series of the runoff, the M-K mutation test to analyze the change in the time series of the runoff and the Morlet continuous complex wavelet transform to analyze the period of the multi-timescale characteristics of the runoff time series $[20,21]$.

\section{Moving Average Method}

To apply the moving average method, we first calculated a mean value over several years, which was designated as the trimmed mean of the middle year. We regressed by 1 year to form a new time segment and computed the average. We applied this procedure to the entire dataset.

\section{$M-K$ Test}

We used the M-K test to analyze the tendency change and the random change in the time series. This test was originally proposed by Mann [22] and Kendall $[23,24]$ and has since been continuously improved to become the method recommended by the World Meteorological Organization for the trend analysis of environmental time series data. This method is widely applied for trend analysis because samples are not required to obey a specified distribution $[25,26]$.

We defined a statistical test quantity, ZC. We determined the variation trend and strength of the series from the correlation between the positive and negative values of $\mathrm{ZC}$ and the threshold value at a given confidence level. A positive $\mathrm{ZC}$ reflects an increase for the time series and a decrease otherwise. The exceedance of $\mathrm{ZC}$ above the threshold value corresponds to a significant variation [27]. We quantified trends by computing the Kendall slope $\beta$. We used the M-K test to perform a mutation test on the series. We determined the approximate time of the change in the series from the intersection of the positive series (the UF curve) and the reverse series (the UB curve) between the confidence levels. In this paper, we adopted a confidence level of $\alpha=0.05$ with a corresponding threshold of \pm 1.96 .

\section{Periodic Analysis Method: Wavelet Analysis}

We used wavelet analysis to analyze the period of runoff variation. The wavelet transform is an applied mathematical method that was developed in the late 1980s [28], and its basic principle is described below. [29]

Let $\Phi(t) \in L^{2}(R)$, where $L^{2}(R)$ represents the real number space with square integrability, i.e., the signal space with limited energy. The Fourier transform of $\Phi(\mathrm{t})$ is denoted by $\psi(\omega)$. If $\psi(\omega)$ satisfies the following condition,

$$
\mathrm{C}_{\Phi}=\int_{\mathrm{R}} \frac{|\Psi(\omega)|^{2}}{|\omega|} \mathrm{d} \omega<\infty
$$

then $\Phi(\mathrm{t})$ is designated as a basic wavelet or a mother wavelet. The generating function $\Phi(\mathrm{t})$ can be expanded and translated to produce a wavelet series.

Table 1. Information about the hydrological stations.

\begin{tabular}{|c|c|c|c|c|}
\hline Station & Station No. & Geographical Location & Altitude $/ \mathrm{m}$ & Test time/ Year-month \\
\hline Goutaizi & 30100200 & $41^{\circ} 39^{\prime} \mathrm{N}, 117^{\circ} 2^{\prime} \mathrm{E}$ & 840 & $1952-5$ \\
\hline Sandaohezi & 30100600 & $40^{\circ} 58^{\prime} \mathrm{N}, 117^{\circ} 42^{\prime} \mathrm{E}$ & 373 & $1953-10$ \\
\hline Luan County & 30101400 & $39^{\circ} 44^{\prime} \mathrm{N}, 118^{\circ} 45^{\prime} \mathrm{E}$ & 22 & $1929-04$ \\
\hline
\end{tabular}



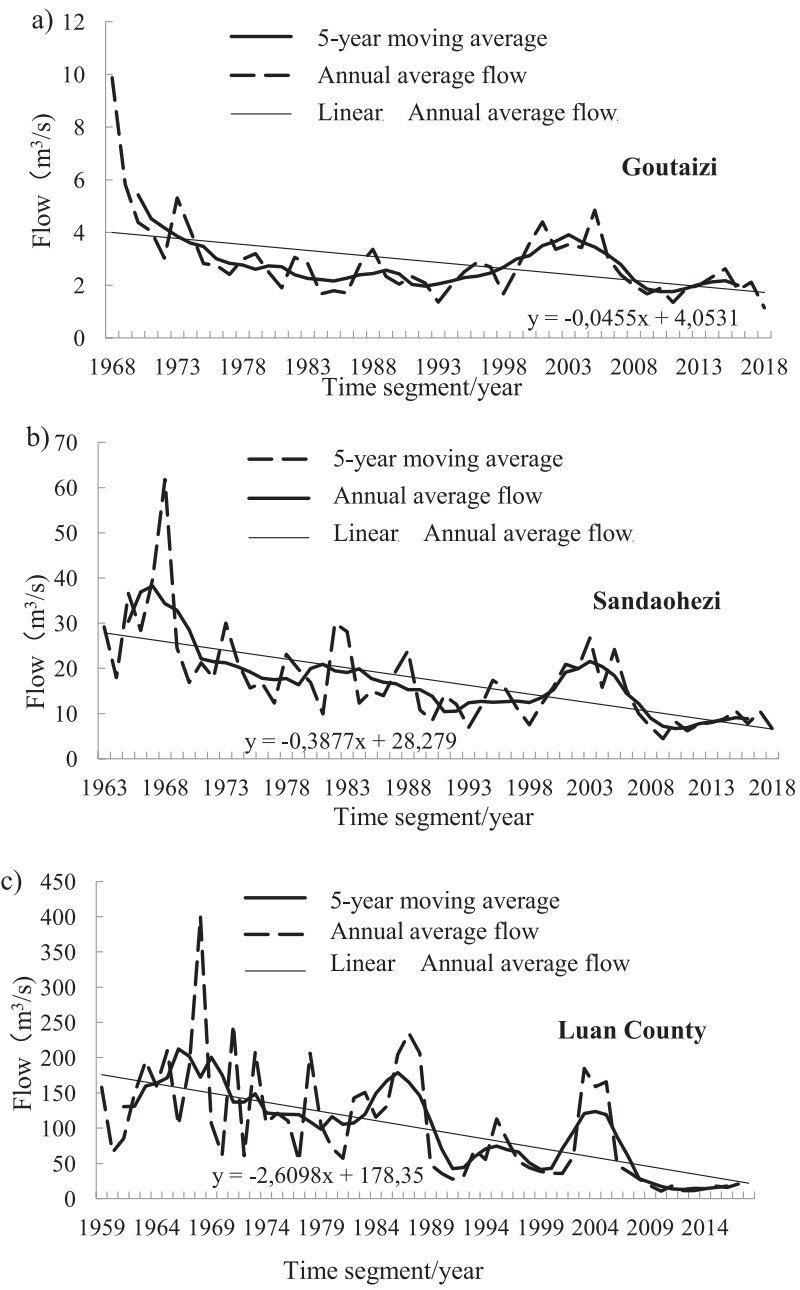

Fig. 2. The 5-year moving average process line results of the runoff volume at the a) Goutaizi, b) Sandaohezi and c) Luan County stations in the Luanhe River Basin.

Under continuous conditions, the wavelet series is given by

$$
\Psi_{a, b}(t)=|a|^{-\frac{1}{2}} \Psi\left(\frac{t-b}{a}\right), a, b \in R, a \neq 0
$$

...where a is the contraction-expansion factor, and b is the translation factor.

The waveform of a Morlet wavelet is similar to that of the time series of precipitation and runoff and exhibits good locality in both the time and frequency domains. Therefore, in this paper, we selected Morlet wavelets to analyze precipitation and the runoff series.
The 1-dimensional continuous Morlet wavelet is given below:

$$
\Phi(\mathrm{t})=\mathrm{e}^{\mathrm{i} \mathrm{w}_{0} \mathrm{t}} \mathrm{e}^{-\mathrm{t}^{2} / 2}
$$

...where $\mathrm{w}_{0}$ is a constant, and $\mathrm{i}$ is an imaginary number. We calculated a scale-time function using the wavelet transform. To accurately explain complex processes, the wavelet variance must be considered in the wavelet analysis to determine the significant period. The wavelet variance reflects the distribution of the fluctuation energy at scale a and can be used to determine the relative intensity of a disturbance at various scales in a time series. The scale at the corresponding peak is called the main time scale of this series, i.e., the main period [30]. Therefore, a wavelet variance graph can be used to confirm the main cycle in a time series. The wavelet variance is calculated as follows:

$$
\operatorname{Var}(a)=\int_{-\infty}^{\infty}\left|W_{f}(a, b)\right|^{2} d b
$$

\section{Results and Discussion}

\section{Trend Analysis of Runoff}

In this study, we adopted the 5-year moving average method to analyze the annual average flow at typical hydrological stations in the Luanhe River Basin. The process line of the 5-year moving average at different stations is shown in Fig. 2. We used a confidence level of $\alpha=0.05$ and conducted the M-K trend test on the time series for the annual runoff and the monthly processes at various hydrological stations. Table 2 shows the test results of the $\mathrm{M}-\mathrm{K}$ rank correlation test method for the trend change of the runoff.

The variation in the average annual flow at the stations can be clearly seen in Fig. 2: although continuous dry-wet alternations can be seen, there is an overall gradual decrease. Table 2 shows significant decreases for the Goutaizi, Sandaohezi and Luan County stations, which is consistent with the test results for the moving average method.

\section{Mutation Analysis of Runoff}

In Fig. 3, the UF curve is mostly below 0, showing a general decrease in the runoff over the entire basin.

Table 2. M-K test results of the runoff volume at the Goutaizi, Sandaohezi and Luan County stations in the Luanhe River Basin.

\begin{tabular}{|c|c|c|c|c|c|}
\hline Station & $\begin{array}{c}\text { Statistical quantity } \\
\text { of test } U\end{array}$ & Significance level $\alpha$ & Threshold $\mathrm{U}_{\alpha / 2}$ & $\begin{array}{c}\text { Determination } \\
\text { result }\end{array}$ & Tendency \\
\hline Goutaizi & -3.41 & 0.05 & 1.96 & $|\mathrm{U}| \mathrm{U}_{\alpha / 2}$ & Significantly decreasing \\
\hline Sandaohezi & -5.46 & 0.05 & 1.96 & $|\mathrm{U}| \mathrm{U}_{\alpha / 2}$ & Significantly decreasing \\
\hline Luan County & -5.54 & 0.05 & 1.96 & $|\mathrm{U}| \mathrm{U}_{\alpha / 2}$ & Significantly decreasing \\
\hline
\end{tabular}


Fig. 3a) shows a slow decrease with a wave-like undulation in the annual average flow at the Goutaizi station. The UF curve exceeds the 0.05 confidence level in 1969, indicating a significant decrease in the annual average flow after this year. The intersection of the UF and UB curves in 1969 indicates an abrupt change at the Goutaizi station during this year.

Fig. 3b) shows the annual average flow at the Sandaohezi station. The UF curve is below 0 everywhere, except for 1968, indicating a decrease with a wave-like undulation for 1963-2018. The UF curve exceeds the 0.05 confidence level after 1975, indicating a significant decrease in the annual average flow after
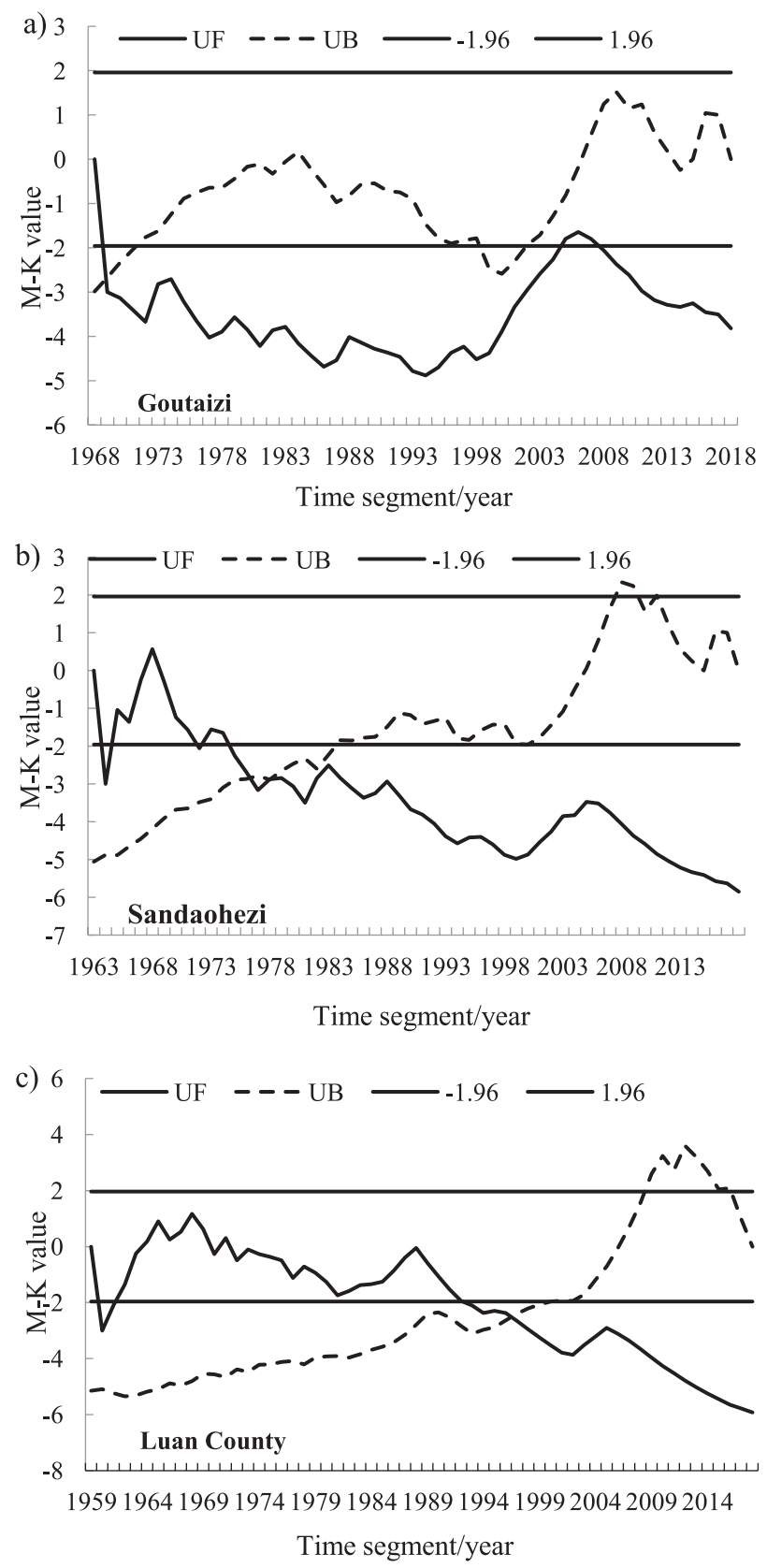

Fig. 3. M-K analysis for the annual runoff volume at different hydrological stations in the Luanhe River Basin: a) Goutaizi station, b) Sandaohezi station, c) Luan County station. this year. The intersection of the UF and UB curves in 1976 indicates an abrupt change at the Sandaohezi station during this year.

Fig. 3c) shows the annual average flow at the Luan County station. The UF curves for 1959-1963 and after 1972 are below 0 , indicating a decrease with a wave-like undulation in the annual average flow for 1959-2018. The UF curve exceeds the 0.05 confidence level after 1993, which indicates a significant decrease in the annual average flow after this year. The intersection of the UF and UB curves in 1997 indicates an abrupt change at the Luan County station during this year.

\section{Periodicity Analysis of Runoff}

We used the MATLAB Morlet wavelet analysis procedure to analyze the periodic features of the annual
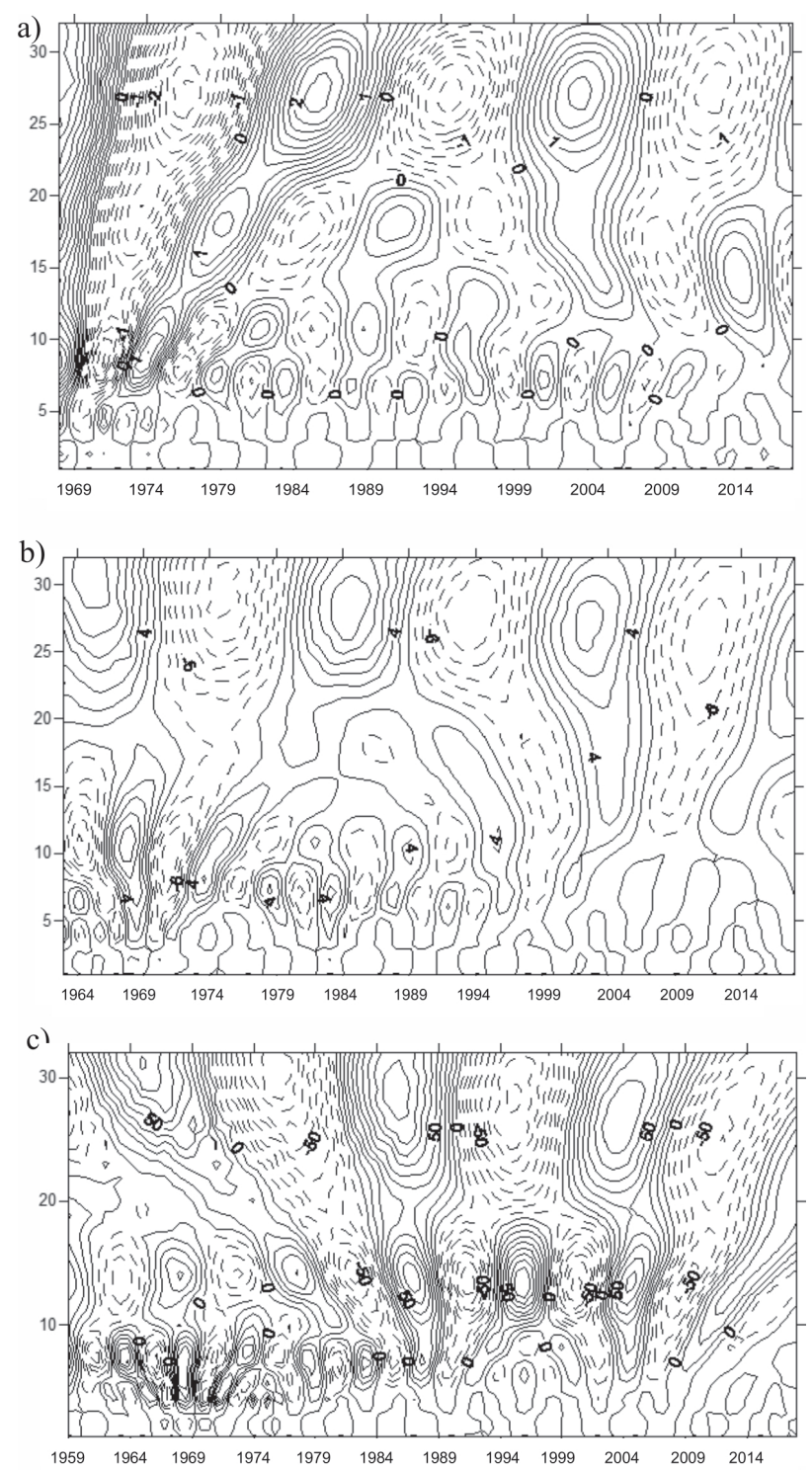

Fig. 4. Real parts of cmor2-1 wavelet coefficients: a) Goutaizi station, b) Sandaohezi station, c) Luan County station. 
precipitation and annual runoff volume at the Goutaizi, Sandaohezi and Luan County stations for 1959-2014. Fig. 4 is a contour map for the wavelet transform analysis of the runoff volume at the three stations. In the real part of the contour map of the wavelet transform, the abscissa is the time (year), and the ordinate is the timescale. The contour curve is the real part of the wavelet coefficient. A positive (negative) real wavelet coefficient represents the wet (dry) season and is shown as a solid (dashed) line. Fig. 5 is a graph of the wavelet coefficient variance versus the scale, that is, the figure shows how the fluctuation energy is distributed for the scale a. This graph is used to determine the main timescales of the hydrological series, i.e., the dominant period.

Fig. 4a) shows multi-timescale characteristics for the runoff evolution process at the Goutaizi station. Periodic variation patterns can be observed at three scales: 22-32 years, 13-21 years and 3-12 years. The 22-32-year scale exhibits a quasicubic oscillation of drywet alternation and the most distinct periodic variation of the three scales, whereas the 13-21-year timescale exhibits a quasiquartic oscillation. The performance of these two timescales is relatively stable during the entire time segment of analysis, indicating a global process. The 3-12-year timescale is relatively distinct for 1979-2012, with alternating wet and dry seasons.

Fig. 4b) shows three scales of periodic variation for the runoff evolution at the Sandaohezi station basin: 20-32 years, 3-19 years and 3-10 years. The 20-32year scale indicates a quasicubic oscillation of drywet alternation, with the most distinct periodic change of the three scales. The performance of this timescale is relatively stable during the entire time segment of analysis and indicates a global process. The 3-19-year timescale is relatively distinct for 1963-1979 with two oscillations. The 3-10-year timescale is relatively distinct for 1979-1994, with alternating wet and dry seasons.

Fig. 4c) shows multi-timescale characteristics for the runoff evolution processes of the Luan County station. Periodic variation patterns are observed on three scales: 20-32 years, 11-19 years and 3-10 years. The 20-32year scale exhibits a quasicubic oscillation of drywet alternation, and there are six oscillations during the 11-19-year timescale. The performance of these two timescales is relatively stable over the entire time segment of analysis and indicates a global process. The 3-10-year timescale is relatively distinct for 1959-1987, with alternating wet and dry seasons.

Fig. 5a) is the wavelet variance graph for the Goutaizi station. There are three relatively distinct peaks corresponding to timescales of 27,18 and 8 years. The highest peak corresponds to the 27-year timescale, which exhibits the strongest oscillation and is the first dominant period of flow change in the basin. The second and third peaks correspond to the 18- and 8-year timescales, which are the second and third dominant periods of flow change, respectively.
Fig. 5b) is the wavelet variance graph for the Sandaohezi station and shows distinct peaks for timescales of 28, 11, 7 and 4 years. The highest peak corresponds to the 28-year timescale, which exhibits the strongest periodic oscillation and is the first dominant period of flow change in the basin. The second, third and fourth peaks correspond to the 11-, 7- and 4-year timescales, which are the second, third and fourth dominant periods of flow change, respectively. The fluctuation of these periods controls the variation characteristics of the flow over the entire time domain.

Fig. 5c) is the wavelet variance graph for the Luan County station and shows four relatively distinct peaks corresponding to timescales of $30,14,7$ and 4 years. The highest peak corresponds to the 30-year timescale, which exhibits the strongest periodic oscillation and is the first dominant period of flow change in the basin. The second, third and fourth peaks correspond to the 14-, 7- and 4-year timescales, which are the second, third and fourth dominant periods of flow change, respectively. The fluctuation in these periods controls
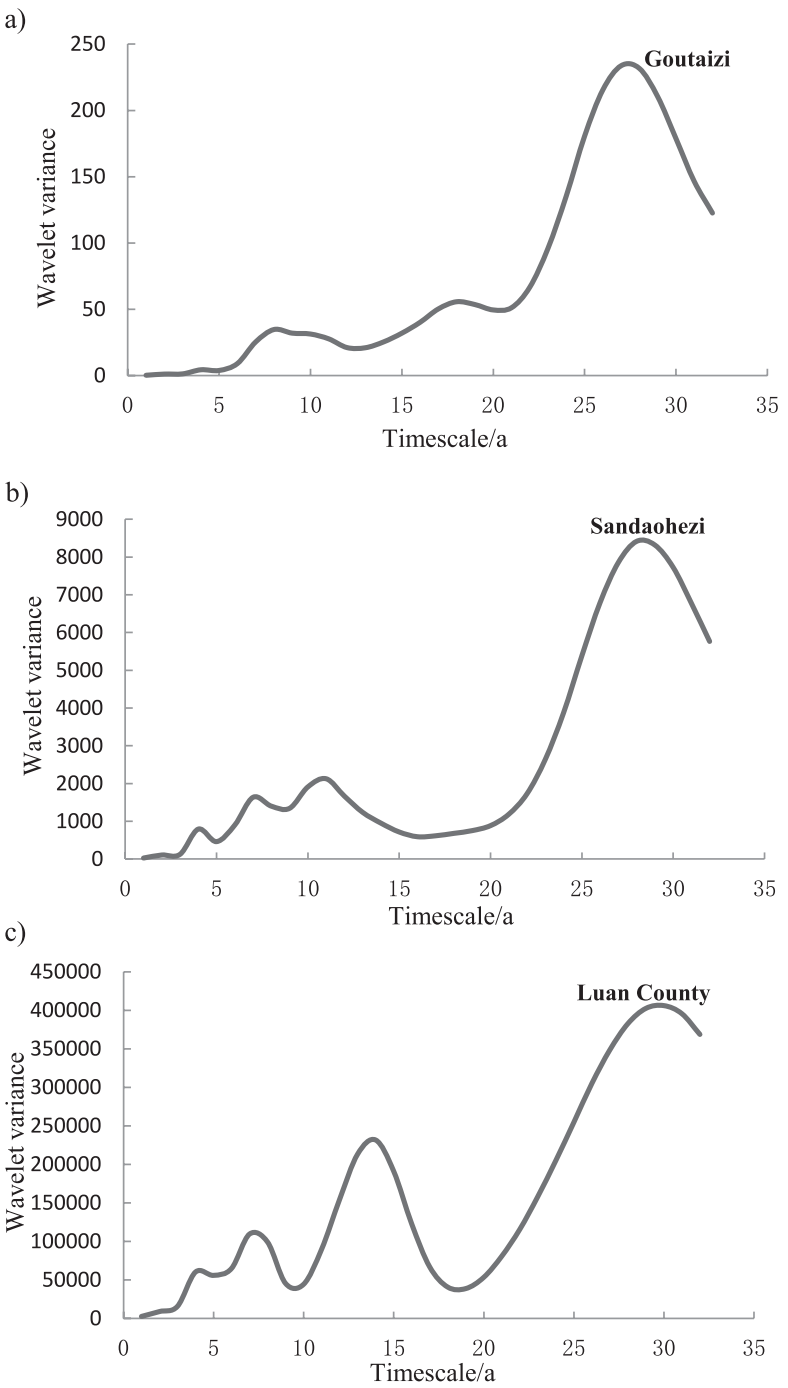

Fig. 5. The variance of Morlet wavelet coefficients: a) Goutaizi station, b) Sandaohezi station, c) Luan County station. 
the variation characteristics of the flow over the entire time domain. Overall, the results for the evolution of the natural runoff of the Luanhe River are in agreement with results in the literature on the long-term evolution of the runoff volume in the Luanhe River Basin [15].

\section{Conclusions}

In this study, a 5-year moving average analysis was used to perform M-K trend and mutation analyses and a Morlet wavelet period analysis for the annual precipitation and annual runoff volume at three representative stations (the Goutaizi, Sandaohezi and Luan County stations) in the Luanhe River Basin for 1959-2018. We can draw the following conclusions from the study results.

(1) The annual runoff volumes at the three stations decrease for 1959-2018.

(2) Abrupt decreases in runoff occurred at the Goutaizi station in 1969 and at the Sandaohezi station in 1976. There was a significant increase in the runoff at the Luan County station after 1997. These changes in runoff are directly associated with land use changes and extreme climatic events under a changing environment.

(3) The significant period of variation for the upper, middle and lower reaches of the Luanhe River are 28, 27 and 30 years, respectively. The periodicity of the runoff evolution is almost synchronized over the entire basin.

\section{Acknowledgements}

This research was supported by project No.41702247 of the National Natural Science Foundation of China, project No. ZJWEU- RWM- 20200201A sponsored by the Open Research Fund of the Key Laboratory for Technology in Rural Water Management of Zhejiang province.

\section{Conflicts of Interest}

The authors declare no conflicts of interest.

\section{References}

1. LI T., HU G., GU Q., ZHOU H. Impact of precipitation and human activities on runoff in Zishui Basin in the past 55 years. Journal of China hydrology, 38 (6), 54, 2018.

2. ZHANG D., WU Y., LI N. Analysis on Evolution Trend of Hydrological Variables in Niyanghe Basin Based on Mann-Kendall Test. China Rural Water and Hydropower, 12 (1), 86, 2017.

3. LV X., ZUO Z., XIAO P., NI Y., SUN J. Effects of Climate Change and Human Activity on Runoff in a Typical
Loess Gullied-Hilly Region Watershed. Polish Journal of Environmental Studies, 27 (2), 779, 2018.

4. WAŁĘGA A., KOWALIK T., BOGDAŁ A. Estimating the Occurrence of Trends in Selected Elements of a Small Sub-Mountain Catchment Hydrological Regime. Polish Journal of Environmental Studies, 25 (5), 2551, 2016.

5. HE L. Effects of Human Activities in the Wei River Basin on the Lower Yellow River, China. Polish Journal of Environmental Studies, 26 (6), 2555, 2017.

6. DOUGLAS E.M., VOGEL R.M., KROLL C.N. Trends in floods and low flows in the United States: impact of spatial correlation. Journal of Hydrology, 240 (1), 90, 2000.

7. Intergovernmental Panel on Climate Change. Fifth Assessment Report: Repod of IPCC[R]. Stockhohn: IPCC, 2013.

8. WANG X., LI P., SU C., CHENG G. Impact of Hydropower Dam Development on River Ecosystems: Ecopath Model Application on the Red River in China as an Example. Polish Journal of Environmental Studies, 26 (6), 2811, 2017.

9. YANG C., LAN Y., WANG N., WANG Q., LI Y. Mountainous Runoff Changes and Climate Factors Analysis of the Shule River Basin in 1958-2015. Scientia Geographica Sinica, 37 (12), 1894, 2017.

10. SUN Y., LI D. Features and response to climatedriven factors of the runoff in the upper reaches of the Weihe River in 1975-2011. Journal of Glaciology and Geocryology, 36 (2), 339, 2014.

11. ZHU H., ZHAO W., KANG M., GUO W. Effect of human activities on flood season runoff in water and soil conservation region. Advances in Water Science, 19 (3), 333, 2008.

12. WANG G., YAN D., HUANG Z., JIN X., PU S. Analysis on the Long-term Evolution of Runoff Volume and Its Affecting Factors in the Luanhe River Basin. Arid Zone Research, 28 (6), 333, 2011.

13. BARLAGE M.J., RICHARDS P.L., SOUSOUNIS P.J. eta1. Impacts of Climate Change and Land Use Change on Runoff from a Great Lakes Watershed. Journal of Great Lakes Research, 28 (4), 568, 2002.

14. MATYSIK M., ABSALON D., RUMAN M. Surface water quality in relation to land cover in agricultural catchments (Liswarta River Basin case study). Polish Journal of Environmental Studies, 24 (1), 175, 2015.

15. XIA J., WANG M. Runoff Changes and Distributed Hydrologic Simulation in the Upper Reaches of Yangtze River. Resources Science, 30 (7), 64, 2008.

16. JIN J., WANG G., LIU C., LIU Y., BAO Z. Future Evolution Trends of Water Resources in Haihe River Basin under the Climate Change. Journal of Noah China University of Water Resources and Electric Power (Natural Science Edition), 37 (5), 1, 2016.

17. YAN Z., SHA J., LIU B., TIAN W., LU J. An Ameliorative Whale Optimization Algorithm for Multi-Objective Optimal Allocation of Water Resources in Handan, China. Water, 10 (1), 87, 2018.

18. XU M., HAN H., KANG S. Modeling Glacier Mass Balance and Runoff in the Koxkar River Basin on the South Slope of the Tianshan Mountains, China, from 1959 to 2009.Water, 9 (2),100, 2017.

19. SHAN C., DONG Z., YANG J., HUANG D., WANG H. Study on River Health Assessment Weight Calculation. Polish Journal of Environmental Studies, 26 (2), online, 2020.

20. ZHANG S., ZHANG H., XIN C., NAN Z. A method for characterizing trends and morphological changes of 
hydrological series. Water Resources Protection, 35 (6), $58,2019$.

21. HOU L., PENG W., QU X., CHEN Q., FU Y., DONG F., ZHANG H. Runoff Changes Based on Dual Factors in the Upstream Area of Yongding River Basin. Polish Journal of Environmental Studies, 28 (1), 143, 2019.

22. MANN H.B. Nonparametric tests against trend. Econometrica, 13 (3), 245, 1945.

23. KENDALL M.G. Rank correlation methods 1975. London: Griffin.

24. WANG J., ZHANG J., LI Y., ZHANG J. Distribution trends of annual runoff distribution in China's six major river basins in the past 50 years. Advances in water science, 19 (5), 656, 2008.

25. CHANG B., HE K., LI R., WANG H., WEN J. Trends, Abrupt Changes, and Periodicity of Streamflow in Qinghai Province, the Northeastern Tibetan Plateau, China. Polish Journal of Environmental Studies, 27 (2), 545, 2018.
26. HAMED K.H., RAO A.R. A modified Mann-Kendall trend test for autocorrelated data. Journal of Hydrology, 204 (1), 182, 1998

27. YUE S., PILON P., CAVADIAS G. Power of the MannKendall and Spearman's rho tests for detecting monotonic trends in hydrological series. Journal of Hydrology, 259 (1), 254, 2002.

28. ALAMGIR KHALIL, SUBHAN ULLAH, SAJJAD AHMAD KHAN, SADAF MANZOOR, ASMA GUL, MUHAMMAD SHAFIQ. Applying Time Series and a Non-Parametric Approach to Predict Pattern, Variability, and Number of Rainy Days Per Month. Polish Journal of Environmental Studies, 26 (2), 635, 2017.

29. ZHANG J., LIU J., JIN J., MA T. Evolution and Trend of Water Resources in Qinghai-Tibet Plateau. Bulletin of Chinese Academy of Sciences, 34 (11), 1264, 2019.

30. XU Y., LI S., CAI Y. Study on the Variation of Precipitation in Hebei Plain Based on Wavelet Analysis. Science in China Ser. D Earth Sciences, 34 (12), 1176, 2004. 